\title{
Licensing Contracts in Hotelling Structure
}

\author{
Tarun Kabiraj ${ }^{1}$, Ching Chyi Lee ${ }^{2}$ \\ ${ }^{1}$ Indian Statistical Institute, Kolkata, India \\ ${ }^{2}$ The Chinese University of Hong Kong, Hong Kong, China \\ E-mail: tarunkabiraj@hotmail.com
}

Received June 1, 2011; revised August 11, 2011; accepted August 22, 2011

\begin{abstract}
This paper discusses the question of optimal licensing contracts in Hotelling structure and focuses on the unique features of this structure in this context. We show that a royalty equilibrium exists if and only if transport cost lies in a specified interval, but the royalty rate can be higher than the amount of cost saving. While fee licensing only is never profitable, the optimal licensing contract consists of both fee and royalty. In equilibrium the market is fully covered with monopolistic goods.
\end{abstract}

Keywords: Technology Transfer, Royalty Licensing, Fee Licensing, Hotelling Structure

\section{Introduction}

Technology transfer from a low cost firm to a high cost firm is a common phenomenon. By transferring its superior technology the patent holder can achieve a larger profit. There is already a vast literature on technology licensing. One aspect of this literature is to discuss the question of optimal licensing contracts ${ }^{1}$. Generally technology transfer occurs under a fee contract or royalty contract, and sometimes the contract takes a hybrid form consisting of both fee and royalty ${ }^{2}$. However, which particular form of contract is optimal from the viewpoint of the transferor depends on a number of factors such as: the structure of the product market, the nature of market competition, the degree of product differentiation, the extent of cost saving, whether the patentee is an insider or outsider, whether there is asymmetric information, etc.

Given the existing literature, it seems that the question of technology licensing in the Hotelling [5] structure is not yet fully explored. One motivation of the present paper is to draw attention to the special features of the Hotelling model in this context as distinct from the other models of product differentiation. The important questions we like to discuss in this paper are the following. Can there be a technology transfer under a fee contract? Does a royalty contract always exist? Is the market fully covered under the optimal licensing contract? Can the

\footnotetext{
${ }^{1}$ See, for instance, Kabiraj [1], Sen and Tauman [2]), and Mukherjee [3].

${ }^{2}$ In a survey of firms, Rostoker [4] finds that $39 \%$ of cases have royalty alone, $13 \%$ have fee alone and the remaining cases have fee plus royalty.
}

optimal royalty rate exceed the extent of cost saving? Can the transferor extract all surplus of the transferee by means of a royalty alone? Is such transfer beneficial to the consumers? We restrict our analysis to the scenario where the patentee is an insider and firms' locations are exogenous. Initially the firms have asymmetric technologies. The low cost firm then designs a contract to transfer its technology to the other firm.

To our knowledge, only two papers, Poddar and Sinha [6] and Matsumura and Matsushima [7], have provided some analysis on the issue of technology licensing in Hotelling structure. While Poddar and Sinha discuss the question of optimal licensing contracts between the two firms, their solution for a royalty contract is incorrectly formulated. And Matsumura and Matsushima examine how licensing activities affect the location of the firms and their incentives for R \& D investment. Both the papers assume a priori that a royalty cannot exceed the amount of cost saving, but neither explains why such an assumption is needed. In our paper we investigate this issue when the royalty rate is endogenously determined. Further, in our analysis there is an outside good; hence we examine whether in equilibrium the market is fully covered with the monopolistic good. In all the models, however, fee licensing is never profitable.

The main results derived in the paper are the following, and it may be pointed out that some of these results are driven by the unique qualities of the Hotelling model of duopoly. For instance, we show that the optimal output and profit levels are independent of the marginal cost of production when the firms are equally efficient; so with 
technology transfer marginal cost has no effect on the equilibrium levels of market share or firm profits. In addition, under transfer the transferee's profit is unaffected by the royalty rate and the transferor's profit is linear in royalty rate. In no other differentiated product models we have these features. In our paper the transport cost plays an important role in determining and characterizing the licensing equilibrium. A royalty licensing equilibrium exists if and only if the transport cost belongs to a specified interval. In equilibrium the market is fully covered; thus segmented market equilibrium will never occur. The optimal royalty rate when licensing equilibrium exists can be higher than the amount of cost reduction. Since the transferor cannot extract all surplus of the transferee by means of a royalty only, a royalty-fee contract is optimal in the Hotelling structure.

To briefly outline the literature in his context, we note that in a homogeneous good duopoly, with the patentee being insider, in equilibrium royalty licensing dominates fee licensing and the optimal royalty is equal to the amount of cost saving (Wang [8]). Then if the model is extended to the case of usual Dixit [9] type product differentiation, qualitative results remain almost unchanged (Wang [10]). One distinctive result, however, is that a drastic innovation may be transferred when the goods are imperfect substitute. Li and Song [11] have studied technology licensing in a vertically differentiated duopoly. It is shown that the high-quality firm always transfers its superior technology to the low-quality firm, irrespective of the forms of the licensing contracts. Finally, Kabiraj and Lee [12] have shown that when the products are both vertically and spatially differentiated a fee licensing can be a profitable option.

The layout of the paper is the following. In section 2 we present the model and results. Finally, section 3 is a conclusion.

\section{Model and Results}

Consider two firms producing homogeneous goods but located at two end points of a Hotelling linear city of length 1 . Assume that firm 1 is located at 0 and firm 2 at 1. Consumers are uniformly distributed over the length of the city; each consumer buys at most one unit of the monopolistic good. We say that the market is fully covered if all consumers buy the good. Assume further that there is an outside competitive good, and the consumer's net utility from it is normalized to zero. Therefore a consumer will buy the monopolistic good if and only if her net utility from it is non-negative.

The utility function of a consumer located at $x \in[0,1]$ is given by

$$
u= \begin{cases}v-t x-p_{1} & \text { if to buy from firm } 1 \\ v-t(1-x)-p_{2} & \text { if to buy from firm } 2\end{cases}
$$

where $v>0$ denotes the basic utility, same for all consumers; $p_{\mathrm{i}}$ is the unit price charged by firm $\mathrm{i}$, and $t>0$ is the Hotelling transport cost of travel per unit distance. We restrict to the scenario where each firm has a positive market share; therefore,

$$
p_{j}-t<p_{\mathrm{i}}<p_{j}+t ; i \neq j .
$$

Let $\bar{x}$ be the consumer indifferent between buying from firm 1 and firm 2,

$$
\bar{x}=\frac{1}{2 t}\left[t+p_{2}-p_{1}\right]
$$

Then the market is fully covered if and only if $2 v \geq p_{1}+p_{2}+t$. This gives demand for firm 1 and firm 2's product as $D_{1}\left(p_{1}, p_{2}\right)=\bar{x}$ and $D_{2}\left(p_{1}, p_{2}\right)=1-\bar{x}$, respectively. On the other hand, the market is segmented if $2 v<p_{1}+p_{2}+t$. This is the situation when some consumers (in particular, the one located at $\bar{x}$ ) fail to buy the monopolistic product. In this case firm i $(\mathrm{i}=1,2)$ faces the demand, $D_{\mathrm{i}}\left(p_{\mathrm{i}}\right)=\frac{v-p_{\mathrm{i}}}{t}$.

Let $c_{\mathrm{i}}$ be the unit cost of production of firm i . Further assume that firm 2 possesses the superior technology; therefore, $c_{2}<c_{1}$. We consider the possibility of technology transfer from firm 2 to firm 1 . First we consider the benchmark case of no technology transfer. Then we examine fee licensing and royalty licensing separately. Finally we discuss the optimal licensing contract.

\subsection{Benchmark Case: No-Transfer of Technology}

Given the demand and cost functions, firm i 's profit function is:

$$
\Pi_{\mathrm{i}}\left(p_{1}, p_{2}\right)=\left(p_{\mathrm{i}}-c_{\mathrm{i}}\right) D_{\mathrm{i}}\left(p_{1}, p_{2}\right) \quad \mathrm{i}=1,2
$$

We assume that both the firms have positive market shares. The firms simultaneously choose their prices, hence they play a Bertrand-Nash game. The equilibrium prices, market shares and profits of the firms are

$$
\begin{gathered}
p_{1}^{N}=\frac{1}{3}\left[3 t+2 c_{1}+c_{2}\right], \quad p_{2}^{N}=\frac{1}{3}\left[3 t+c_{1}+2 c_{2}\right] \\
D_{1}^{N}=x^{N}=\frac{1}{6 t}\left[3 t+c_{2}-c_{1}\right], \\
D_{2}^{N}=1-x^{N}=\frac{1}{6 t}\left[3 t+c_{1}-c_{2}\right] \\
\pi_{1}^{N}=\frac{1}{18 t}\left[3 t+c_{2}-c_{1}\right]^{2}, \quad \pi_{2}^{N}=\frac{1}{18 t}\left[3 t+c_{1}-c_{2}\right]^{2}
\end{gathered}
$$


Then, the assumption that each firm has a positive market share means that

$$
t>\frac{c_{1}-c_{2}}{3} \equiv \underline{t}
$$

\subsection{Technology Transfer under a Fee Contract}

Here the game is the following. Firm 2 offers a fee contract to firm 1. If it is accepted, the superior technology is transferred and the market structure becomes symmetric duopoly, with each firm having low unit cost of production. And if the contract is rejected (this is equivalent to giving a no-technology transfer offer), the market structure becomes asymmetric duopoly as given in the benchmark model.

Now the market-operated profits of the firms under the fee licensing contract are:

$$
\pi_{1}^{F}=\frac{t}{2}=\pi_{2}^{F}
$$

Then technology transfer under the fixed fee contract $F$ will be mutually profitable if and only if $\pi_{2}^{F}+F>\pi_{2}^{N}$ and $\pi_{1}^{F}-F \geq \pi_{1}^{N}$. Then $\exists F>0$ if and only if

$$
\pi_{1}^{F}+\pi_{2}^{F}>\pi_{1}^{N}+\pi_{2}^{N}
$$

But this condition is never satisfied. Hence in the Hotelling structure fee licensing will never occur in equilibrium ${ }^{3}$.

\subsection{Technology Transfer under a Royalty Contract}

Now consider the possibility of technology transfer from firm 2 to firm 1 under a royalty contract. The game is the following. First, firm 2 proposes a royalty, $r$, per unit of firm 1's output. In the second stage firm 1 either accepts or rejects the contract; it accepts if it is not worse off in the post-transfer situation. Then in the third stage they choose prices simultaneously. Therefore, rejecting the contract means it is no-transfer equilibrium outcome.

First consider royalty equilibrium with full market coverage. Given any $r$, the third stage problems of firm 1 and firm 2 are respectively,

$$
\max _{p_{1}}\left(p_{1}-c_{2}-r\right) D_{1}\left(p_{1}, p_{2}\right)
$$

and

$$
\max _{p_{2}}\left(p_{2}-c_{2}\right) D_{2}\left(p_{1}, p_{2}\right)+r D_{1}\left(p_{1}, p_{2}\right)
$$

The third stage outcomes are:

$$
p_{1}^{R}(r)=p_{2}^{R}(r)=t+c_{2}+r
$$
${ }^{3}$ This result is already derived in Poddar and Sinha [6]. However, fee
licensing can be profitable if the products are both vertically and horizontally differentiated (Kabiraj and Lee [12]).

$$
\begin{gathered}
D_{1}^{R}(r)=D_{2}^{R}(r)=\frac{1}{2} \\
\pi_{1}^{R}(r)=\frac{t}{2} \text { and } \pi_{2}^{R}(r)=\frac{t}{2}+r
\end{gathered}
$$

Recall that the assumption of full market coverage requires that $2 v \geq p_{1}^{R}(r)+p_{2}^{R}(r)+t$, i.e.,

$$
r \leq v-c_{2}-\frac{3}{2} t \equiv r^{R}
$$

We further need to restrict that $r^{R}>0$, i.e.,

$$
t<\frac{2}{3}\left(v-c_{2}\right) \equiv \bar{t}
$$

Note the unique features of the Hotelling structure in licensing equilibrium. Here $D_{1}^{R}, D_{2}^{R}$ and $\pi_{1}^{R}$ are independent of $r$, but $p_{1}^{R}, p_{2}^{R}$ and $\pi_{2}^{R}$ are linear and increasing in $r$. Hence firm 2 has an incentive to increase $r$ as much as possible; in response firm 1 will just raise its price linearly without losing its market share and profits as long as the indifferent consumer $\bar{x}$ continues to buy. Therefore, the optimal royalty $r^{R}$ is determined corresponding to $u(\bar{x})=0$. This gives

$$
r^{R}=v-c_{2}-\frac{3}{2} t
$$

Given that $t>\underline{t}$ (which ensures that both the firms' market shares are positive and profits are strictly positive), we have $\pi_{1}^{R}(r)>\pi_{1}^{N}$. Therefore, in the second stage any royalty $r \leq r^{R}$ is acceptable to firm 1. Given (4), there are parameter values under which $r^{R}-\left(c_{1}-c_{2}\right)>0$ is possible; therefore the royalty rate can exceed the amount of cost saving.

Now firm 2 will offer the royalty $r^{R}$ iff $\pi_{2}^{R}(\hat{r})>\pi_{2}^{N}$, that is

$$
\begin{aligned}
& r^{R}+\frac{t}{2}>\frac{1}{18 t}\left(3 t+c_{1}-c_{2}\right)^{2} \\
& \Rightarrow \quad L H S(t) \equiv v-c_{2}-\frac{3}{2} t>\frac{\left(c_{1}-c_{2}\right)}{3}+\frac{\left(c_{1}-c_{2}\right)^{2}}{18 t} \\
& \equiv R H S(t)
\end{aligned}
$$

Check that $L H S(t)$ is linear and decreasing in $t$, and $R H S(t)$ is convex and decreasing, with

$R H S(t) \rightarrow \frac{\left(c_{1}-C_{2}\right)}{3}$ as $t \rightarrow \infty$, and $\operatorname{LHS}(\underline{t})>R H S(\underline{t})$.

Therefore,

$$
\exists \hat{t}, \underline{t}<\hat{t}<\bar{t}, \mid \operatorname{LHS}(t)>\operatorname{RHS}(t) \forall t \in(\underline{t}, \hat{t})
$$

This is shown in Figure 1. Thus royalty equilibrium is the subgame perfect Nash equilibrium outcome of this game if the transport cost lies in the specified interval. This gives the first result of our paper.

Proposition 1: Technology transfer under the royalty contract with full market coverage is mutually profitable 


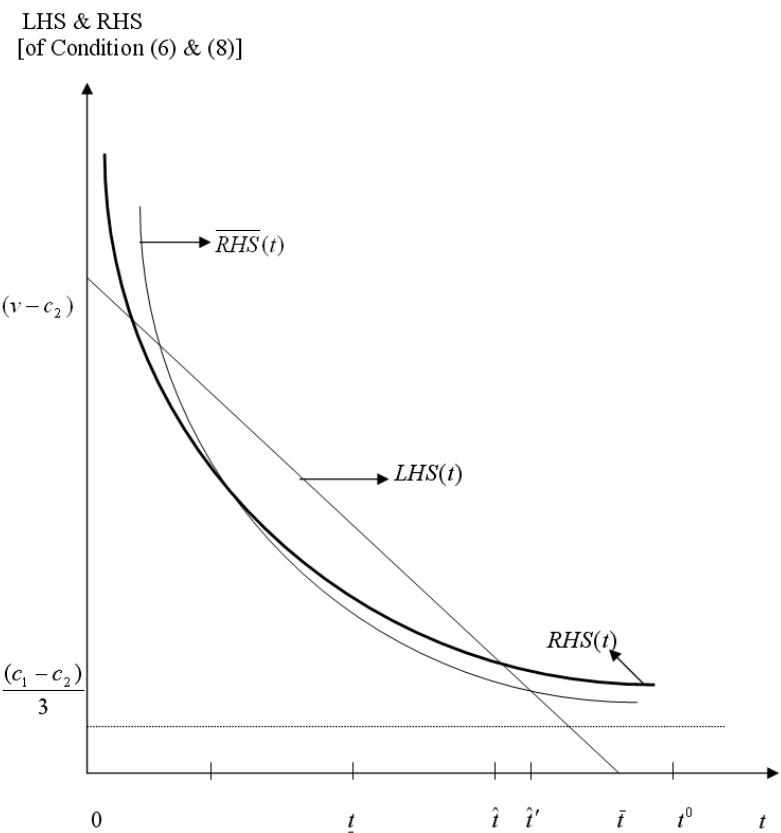

Figure 1. Transport cost and licensing contracts.

if and only if $t \in(\underline{t}, \hat{t})$. The optimal royalty rate is $r^{R}$.

It also follows from the proposition that there will be no royalty licensing with full market coverage if $t \geq \hat{t}$. To examine the possibility of royalty equilibrium when the market is not fully covered, we need to restrict to the scenario where in equilibrium, $2 v<p_{1}+p_{2}+t$. We have derived the following result. The proof is given in the Appendix.

Proposition 2: In the royalty model discussed above, there exists no equilibrium in which the market is not fully covered.

Further note that $2 v<p_{1}+p_{2}+t \Leftrightarrow t>\frac{3}{4}\left(v-c_{2}\right) \equiv t^{0}$ (see (A1) in the Appendix), and then we have, $\hat{t}<t^{0}$. Therefore, in the Hotelling structure if royalty licensing is ever mutually profitable to the firms, it is always optimal to cover the market fully, and such an equilibrium will exist if and only if $t \in(\underline{t}, \hat{t})$.

Proposition 3: In a Hotelling structure with uniform distribution of consumers, the optimal royalty contract is $r^{R}$, and in equilibrium, the market is fully covered.

\subsection{The Optimal Licensing Contract}

Consider the full game. First, firm 2 decides whether to license its technology to its product market rival. If to transfer, it decides whether to offer a fee licensing contract, a royalty licensing contract or a mixture of both.

${ }^{4}$ Note that $\overline{R H S}(t) \underset{<}{<} R H S(t) \Leftrightarrow t \frac{<\frac{\left(c_{1}-c_{2}\right)}{>}}{6}$.
Finally the firms compete in prices. So we search for the subgame perfect equilibrium outcome of this game.

We have already shown that under spatial competition with uniform distribution of consumers, a fee licensing is never profitable. And a royalty contract, when it is profitable, leaves a surplus profit for the transferee, because $\pi_{1}^{R}(r)>\pi_{1}^{N}$. Can the transferor extract this surplus by a mixture of both royalty and fixed fee, that is, by offering a royalty-fee contract $(r, F)$ ? It is easily understood that the optimal royalty and fixed fee will be $r^{R}$ and $F^{R}$, where

$$
F^{R}=\pi_{1}^{R}(r)-\pi_{1}^{N}=\frac{\left(c_{1}-c_{2}\right)\left(6 t-c_{1}+c_{2}\right)}{18 t}
$$

Then firm 2's profitability condition becomes

$$
\begin{gathered}
\pi_{2}^{R}\left(r^{R}, F^{R}\right)=\pi_{2}^{R}\left(r^{R}\right)+F^{R}>\pi_{2}^{N} \\
\Leftrightarrow L H S(t) \equiv v-c_{2}-\frac{3}{2} t>\frac{2\left(c_{1}-c_{2}\right)^{2}}{18 t} \equiv \overline{R H S}(t)
\end{gathered}
$$

This is satisfied ${ }^{4}$ for all $t \in\left(\underline{t}, \hat{t}^{\prime}\right)$ where $\hat{t}<\hat{t}^{\prime}<\bar{t}$, as shown in Figure 1. This gives the final result of the paper:

Proposition 4: Given $t \in\left(\underline{t}, \hat{t}^{\prime}\right)$, the optimal licensing contract under spatial competition is $\left(r^{R}, F^{R}\right)$; there will be no licensing if $t \notin\left(\underline{t}, \hat{t}^{\prime}\right)$.

Note that the availability of a hybrid contract in fact relaxes the constraint of technology transfer, because now the interval of $t$ becomes bigger.

\section{Conclusions}

In the Hotelling structure fee licensing is never profitable, but a royalty equilibrium always exists if the transport cost lies in a specified interval. The unique feature of the Hotelling structure is that under technology transfer the transferee's profit is independent of the royalty rate and the transferor's payoff is a linear function of the royalty rate. Therefore, if there is no restriction on the upper bound of royalty, the transferor, under the optimal licensing contract, raises the royalty as high as possible subject to the marginal indifferent consumer deriving zero utility. However, a royalty-fee contract is required if to extract all surplus of the transferee. In any case, in equilibrium the market is fully covered.

Finally, to make a comment on consumers' welfare we may note that in royalty equilibrium all consumers buy the monopolistic good, but they are to pay a higher price for the good in the post-transfer equilibrium. Then to protect the interest of the consumers in such a situation an upper restriction on the royalty rate is perhaps needed.

\section{Acknowledgements}

We are greatly indebted to the referee of this journal for 
his valuable suggestions and comments on the earlier draft. We shall, however, be held responsible for any remaining errors.

\section{References}

[1] T. Kabiraj, "Technology Transfer in a Stackelberg Structure: Licensing Contracts and Welfare," The Manchester School, Vol. 73, No. 1, 2005, pp. 1-28.

doi:10.1111/j.1467-9957.2005.00421.x

[2] D. Sen and Y. Tauman, "General Licensing Schemes for a Cost-Reducing Innovation," Games and Economic Behavior, Vol. 59, No. 1, 2007, pp. 163-186. doi:10.1016/j.geb.2006.07.005

[3] A. Mukherjee, "Competition and Welfare: The Implications of Licensing," The Manchester School, Vol. 78, No. 1, 2010, pp. 20-40. doi:10.1111/j.1467-9957.2009.02126.x

[4] M. Rostoker, "A Survey of Corporate Licensing", IDEA: The Journal of Law and Technology, Vol. 24, No. 2, 1984, pp. 59-92.

[5] H. Hotelling, "Stability in Competition," Economic Journal, Vol. 39, No. 153, 1929, pp. 41-57. doi: $10.2307 / 2224214$

[6] S. Poddar and U. Sinha, "On Patent Licensing in Spatial
Competition," The Economic Record, Vol. 80, No. 249, 2004, pp. 208-218.

doi:10.1111/j.1475-4932.2004.00173.x

[7] T. Matsumura and N. Matsushima, "On Patent Licensing in Spatial Competition with Endogenous Location Choice," 2008. http://www.iss.u-tokyo.ac.jp/ matsumur/LI.pdf

[8] X. H. Wang, "Fee versus Royalty Licensing in a Cournot Duopoly Model," Economics Letters, Vol. 60, No. 1, 1998, pp. 55-62. doi:10.1016/S0165-1765(98)00092-5

[9] A. Dixit, "A Model of Duopoly Suggesting a Theory of Entry Barriers," Bell Journal of Economics, Vol. 10, No. 1, 1979, pp. 20-32. doi:10.2307/3003317

[10] X. H. Wang, "Fee versus Royalty Licensing in a Differentiated Cournot Duopoly," Journal of Economics and Business, Vol. 54, No. 2, 2002, pp. 253-266. doi:10.1016/S0148-6195(01)00065-0

[11] C. Li and J. Song, "Technology Licensing in a Vertically Differentiated Duopoly," Japan and the World Economy, Vol. 21, No. 2, 2010, pp. 183-190. doi:10.1016/j.japwor.2008.04.002

[12] T. Kabiraj and C. C. Lee, "Technology Transfer in a Duopoly with Horizontal and Vertical Product Differentiation," Trade and Development Review, Vol. 4, No. 1, 2011, pp. 19-40. 


\section{Appendix}

To examine the possibility of royalty equilibrium when the market is not fully covered let us restrict to the scenario where in equilibrium, $2 v<p_{1}+p_{2}+t$.

Consider local monopoly of firm 1 under technology transfer. For any acceptable $r$, firm 1's problem is:

$$
\max _{p_{1}}\left(p_{1}-c_{2}-r\right) \frac{v-p_{1}}{t}
$$

The corresponding product price and market share of firm 1 are, respectively,

$$
\tilde{p}_{1}(r)=\frac{1}{2}\left(v+c_{2}+r\right) \text { and } \tilde{D}_{1}(r)=\frac{1}{2 t}\left(v-c_{2}-r\right)
$$

Since now two markets are segmented, the licensing revenue maximizing royalty rate will be $\tilde{r}=\operatorname{argmax} r \tilde{D}_{1}(r)$, where

$$
\tilde{r}=\frac{v-c_{2}}{2}
$$

The corresponding equilibrium price, market share and profit of firm 1 are:

$$
\tilde{p}_{1}(\tilde{r})=\frac{1}{4}\left(3 v+c_{2}\right), \quad \tilde{D}_{1}(\tilde{r})=\frac{1}{4 t}\left(v-c_{2}\right)
$$

and

$$
\tilde{\pi}_{1}(\tilde{r})=\frac{1}{16 t}\left(v-c_{2}\right)^{2}
$$

and the royalty income of firm 2 is,

$$
\tilde{r} \tilde{D}_{1}(\tilde{r})=\frac{1}{8 t}\left(v-c_{2}\right)^{2}
$$

Firm 2's profit from its segmented market is solved from:

$$
\max _{p_{2}}\left(p_{2}-c_{2}\right) \frac{v-p_{2}}{t}
$$

This gives:

$$
\tilde{p}_{2}=\frac{1}{2}\left(v+c_{2}\right), \quad \tilde{D}_{1}=\frac{1}{2 t}\left(v-c_{2}\right)
$$

and

$$
\tilde{\pi}_{2}=\frac{1}{4 t}\left(v-c_{2}\right)^{2}
$$

Hence, firm 2's total payoff under royalty licensing is:

$$
\tilde{\Pi}_{2}=\tilde{\pi}_{2}+\tilde{r} \tilde{D}_{1}(\tilde{r})=\frac{3}{8 t}\left(v-c_{2}\right)^{2}
$$

Finally, the licensing contract $\tilde{r}$ with local monopoly will be an equilibrium contract iff the following three conditions hold simultaneously. First, the assumption that each firm has local monopoly requires $2 v<\tilde{p}_{1}+\tilde{p}_{2}+t$, i.e.,

$$
t>\frac{3}{4}\left(v-c_{2}\right) \equiv t^{0}
$$

Second, the contract on $\tilde{r}$ is acceptable to firm 1 iff $\tilde{\pi}_{1}(\tilde{r}) \geq \pi_{1}^{0}$, i.e.,

$$
t \leq \frac{v-c_{2}}{2 \sqrt{2}}+\frac{c_{1}-c_{2}}{3} \equiv t_{1}
$$

Third, offering the licensing contract $\tilde{r}$ is profitable to firm 2 iff $\tilde{\Pi}_{2}>\pi_{2}^{0}$, i.e.,

$$
t \leq \frac{\sqrt{3}}{2}\left(v-c_{2}\right)-\frac{c_{1}-c_{2}}{3} \equiv t_{2}
$$

These three conditions (A1) through (A3) will be satisfied simultaneously iff

$$
\min \left\{t_{1}, t_{2}\right\}>t^{0}
$$

Therefore,

$$
t_{2} \frac{\geq}{<} t_{1} \Leftrightarrow \frac{3}{4}\left(v-c_{2}\right) \frac{(2 \sqrt{3}-\sqrt{2})}{2} \geq \frac{c_{1}-c_{2}}{3}
$$

Finally, we can check that $\min \left\{t_{1}, t_{2}\right\}<t^{0}$; therefore condition (A4) is never satisfied. This proves Proposition 2. 